\title{
PRÁTICAS DISCURSIVAS DA DIVERSIDADE SEXUAL E POLÍTICAS CURRICULARES PARA A EDUCAÇÃO BÁSICA
}

\author{
José Rafael Barbosa RODRIGUES ${ }^{1}$ \\ Universidade Federal Do Pará-UFPA \\ rafaelrodrigues92@outlook.com \\ Josenilda Maria Maués da SILVA ${ }^{2}$ \\ Universidade Federal Do Pará-UFPA \\ josimaues@gmail.com
}

Resumo: A presente escrita vincula-se aos estudos realizados no Grupo de Estudos e Pesquisas em Diferença e Educação - DIFERE, vinculado ao Programa de Pós Graduação em Currículo e Gestão da Escola Básica PPEB/ICED/UFPA. A investigação intenta problematizar as práticas discursivas da Diversidade Sexual, do respeito e da tolerância, alinhadas ainda à lógica identitária. $O$ estudo investe no exame dos modos como esses textos curriculares operam e produzem, formas viáveis de experimentação do corpo, do gênero $e$ da sexualidade, agindo assim, como biopolíticas que governam e demandam cuidados de si, instituem regras para a viabilidade e para a inclusão do sujeito-outro da educação, em especial, a população LGBT. Do ponto de vista teórico-metodológico, tratase de um investimento de cunho teórico que opera com uma revisão bibliográfica com ênfase em abordagens de cunho pósestruturalista que investem no Pensamento da Diferença em Educação utilizando ferramentas analíticas das formulações de Michel Foucault.

Palavras-chave: Diferença. Politicas Curriculares. Diversidade Sexual. Resistência.

\begin{abstract}
This paper is linked to the studies carried out in the Group of Studies and Research in Difference and Education DIFERE, linked to the Graduate Program in Curriculum and Management of the Basic School - PPEB / ICED / UFPA. The research tries to problematize the discursive practices of Sexual Diversity, respect and tolerance, still aligned with the identity logic. The study invests in examining the ways in which these curricular texts operate and produce viable forms of experimentation on the body, gender and sexuality, thus acting as biopolitics that govern and demand self-care, establish rules for feasibility and inclusion of the other subject of education, especially the LGBT population. From the theoretical-methodological point of view, it is a theoretical investment that works with a bibliographical revision with emphasis on post-structuralist approaches that invest in the Thought of Difference in Education using analytical tools of the formulations of Michel Foucault.
\end{abstract}

Keywords: Difference. Curricular Policies. Sexual diversity. Resistance

\footnotetext{
${ }^{1}$ Graduado em Pedagogia pela UFPA, membro do Grupo de Estudos e Pesquisas em Diferença em Educação DIFERE/UFPA e do Grupo de Estudos e Pesquisas em Currículo e Formação de Professores na Perspectiva da Inclusão -INCLUDERE/UFPA. Mestrando no Programa de Pós-Graduação em Currículo e Gestão da Escola Básica - PPEB/UFPA.

${ }^{2}$ Doutora em Educação (Currículo) pela PUC/SP. Docente do Programa de Pós-Graduação em Currículo e Gestão da Escola Básica - PPEB/ICED/UFPA. Coordenadora adjunta do PARFOR/UFPA.
} 


\section{Introdução}

Nas últimas décadas, algumas pesquisas no campo educacional tem mostrado a relação da Pedagogia, a escola e do currículo como dispositivos que, no contexto da modernidade, produzem discursos, instituições e práticas que fabricam e disciplinam os sujeitos, os corpos e os modos de vida pelas mais diversas forças, forjando em todos nós as diferenças políticas, culturais, sociais, sexuais e performáticas que nos constituem.

A Pedagogia, por exemplo, como atesta Costa (2010), se configura como um discurso que dispõe de práticas e saberes sobre os sujeitos e seus corpos para administra-los e governalos. Da mesma forma, Louro (2013), tem mostrado como as diferenças de gênero e sexuais são processos oriundos de políticas culturais e práticas discursivas, que encontram na escola e no currículo formas muito específicas e sutis de modelar as formas de ser.

De toda forma, a pesquisa no campo curricular da educação básica tem mostrado como a pedagogia que tem o poder de educar corpos, instituir verdades, e dizer de um sujeito ético/moral produzido pelas mais diversas vontades de saber, e pelos sinuosos jogos de poder, mobilizados para produzir mecanismos de controle das populações.

Como anunciado por Corazza (2001), o discurso educacional brasileiro tem sido marcado em suas pesquisas, em especial no campo curricular, por uma tonalidade críticadenuncia. Busca-se, sempre, denunciar o estado crítico atual do currículo, evidenciando suas falhas, suas impotências, erros, e muitas vezes, o que há "por trás" de uma determinada proposta curricular. Afinal, a quem interessa este ou aquele modelo de currículo? O que há por de trás dele? Qual lógica? Tende-se a demonstrar, da mesma forma, aquilo que o currículo é, e não é. Não é inclusivo, não é crítico-reflexivo, não é emancipador, não é libertador. Mas é machista, é homofóbico, é racista, é reprodutor de desigualdades sociais. Da mesma forma, após analisar o que há por trás de um currículo, dizer o que ele é, e o que não é, buscam apontar algumas alternativas para o "problema" do currículo. É preciso, então, reformar o currículo, apresentar soluções, reparos, alternativas. É necessário dizer de um currículo, uma escola e um sujeito crítico, liberto, emancipado, livre. E assim são produzidos currículos e sujeitos. É preciso indicar um caminho que talvez seja o mais coerente para um projeto de sociedade que se quer. Denuncia, problema, solução.

Não é intensão deste escrito depreciar estas pesquisas e os avanços que elas tem dado ao campo do reconhecimento de direitos. Ao contrário. O que se pretende aqui é fazer uma análise de outra ordem, revirando alguns pressupostos políticos, teóricos e metodológicos. Para além do denuncismo do que o currículo não é, o desejo de pesquisa busca encontrar a positividade de um currículo, e não apenas a negação dele. Não buscando o que há por trás de 
um discurso curricular, mas, antes de tudo, buscando saber o que ele produz, que sujeitos forma, que práticas são instituídas, que modos de vida, éticas e estéticas de existências são legitimadas, quais conhecimentos são legitimados, quais experiências são vividas.

No limiar dos bons encontros com o desejo, com a experiência e com a diferença na educação básica, a pesquisa investe na mobilização de um pensamento que ponha em movimento o sedentarismo curricular-identitário, recorrente nas atuais políticas educacionais, alocadas nas práticas discursivas de governamento da vida e na gerência do corpo e do desejo sexual. Apontando na positividade do currículo como resistência ética e estética, buscamos flagrar as linhas de fuga e das potências criadoras-experimentadoras do fetichismo curricular na produção política-performática da existência e dos modos de vida produzidos no, com e pelo acontecimento curricular. Em uma aproximação filosófica com o pensamento da Diferença em Educação, a partir das lentes foucaultianas, e das ferramentas para o "corte", objetivamos atritar a produção discursiva-curricular para a educação básica, em confluência ao enfrentamento da captura da vida, e na exaltação da criação do desejo e da potência poética-estética de outros modos de ser.

\section{Práticas discursivas da diversidade sexual: lentes teórico-metodológicas}

Uma das análises na qual Foucault investiu com bastante vigor em sua trajetória, faz referência ao modo como os corpos são regulados na contemporaneidade por múltiplos dispositivos e formas de gestão da vida. Em suas investigações genealógicas, o filósofo procurou compreender como a economia e a política agem sobre o corpo, e sobre os processos de docilização destes. Para isto, Foucault procurou compreender antes como o poder é exercido na modernidade (proibição, interdição, repressão), e os efeitos do poder disciplinar, e, posteriormente, os efeitos do biopoder na regulação/construção/governamento dos corposmentes deste tempo: a biopolítica.

E o que opera a biopolítica? A biopolítica, como o biopoder, se ocupa de governar os processos de nascimento, óbitos, taxas de reprodução e natalidade, taxas de longevidade, e suas reverberações na economia política. E para Foucault (1989), o biopoder foi indispensável para o capitalismo, que só pode ser garantido, pelo controle do corpo, e pelo ajustamento da população aos processos econômicos.

O capitalismo, segundo o filósofo, exigiu muito mais do que o controle dos corpos, foram necessárias técnicas de exercício de poder capazes de sujeitar a vida, sem perde-la de controle. E é neste contexto que o filósofo destaca o surgimento dos aparelhos e instituições do 
Estado, capazes desses assujeitamentos, a família, o Exército, a polícia, as escolas, a medicina. E são estes aparelhos que agem também como instrumentos de segregação e hierarquização social, produzindo relações de dominação e hegemonização.

Não foi por outro dispositivo, se não pelo da sexualidade que se conseguiu, então, instituir uma política de controle e governamento da população. Isto, porque a sexualidade se encontra na linearidade entre os dois eixos por onde se desenvolveu a tecnologia política da vida. Se por um lado faz parte do estatuto de dominação individual do corpo, a sexualidade, por outro, faz parte das disposições à regulação da vidas das populações.

$\mathrm{Na}$ formação das teias de regulação da população se forma também uma economia política, e consequentemente, uma análise-controle das condutas. É nesta inquisição do dito sobre o sexo, e das interrogações que podem ser ditas sobre ele, que Foucault experimenta em suas análises, que este sexo, um dia, foi flagrado por um certo dispositivo. Um mecanismo de controle e regulação que "[..] o faz dizer a verdade de si e dos outros num jogo em que o prazer se mistura ao involuntário, e o consentimento à inquisição" (FOUCAULT, 1989, p.85).

Gerenciar um corpo pelo dito da sexualidade, pelo discursos proibidos, pelas práticas legitimadas, força-nos a pensar no que no contexto da modernidade é dito sobre os corpos e da sexualidade da população LGBT. Corpos e performances abjetas que fogem da norma comum também podem ser observadas. Mas qual a utilidade delas para o capital? Não se trata apenas de nega-las, dizer-lhes ilegítimas, mas antes de tudo, controla-las, regula-las, administra-las. De que outra forma governar um corpo, sem dizer sobre ele? Ou, dizer uma verdade sobre ele, exercer poder sobre ele. Aí, neste ponto, no do governo de si e dos outros, figura-se uma outra problemática, ou um outro jogo de poder, o da governamentalidade, a arte de governar.

Em sua microfísica do poder, Foucault (1979), fala sobre a governamentalidade como a arte do governo dos corpos de que fala, e sobre os dispositivos como instituições, linguagem, práticas, discursos, aparelhos, tecnologias, que permitem exercer uma determinada forma de poder, que tem como alvo, a população.

Butler (2015) em uma análise mais específica sobre identidade e performances de gênero e sexualidade, coloca em questão a conduta e a filosofia moral, em seus escritos. Para a filósofa, em uma genealogia da violência ética, os regimes de verdade serão uma relação consigo mesmo. Portanto, por em questão um regime de verdade, é colocar em questão a verdade de si, e por efeito, por em questão a verdade dita e o relato feito por si mesmo. Se questionado o regime de verdade, questionado também estará o regime de fabricação da condição ontológica de si.

Os escritos de Butler, levam-nos sempre as questões relativas a formação da identidade e da subjetividade. Em especial, a filósofa, leva em consideração os processos pelos quais 
somos formados como sujeitos sexuados e generificados. Ou seja, os dispositivos de poder pelos quais somos levados (construídos para nós, e por nós mesmos) a assumir performancesidentidades como sujeitos do sexo, e de gênero. De forma geral, Butler busca flagrar os regimes de verdade e de poder (e tal como Foucault, atravessados pelo saber), que forjam nossas identidades e performances como sujeitos de uma certa sexualidade, e de uma certa conduta social, pelo que é dito pelos outros, e também, pelo que é dito sobre si mesmo.

A performatividade, como atesta Butler (2008), está relacionada a "experiência individual", o processo pelo qual um indivíduo assume sua posição como sujeito. Para a filósofa, é pela linguagem e pelo discurso que os dispositivos de governo das performances identitárias são fabricadas. Em um investimento na genealogia da ética do sujeito, é possível compreender que sexo e gênero, são efeitos, e não apenas causas.

O sujeito-efeito é produção dos discursos e práticas, e as instituições não são produtos de nossas vontades, mas, pelo contrário, o sujeito é efeito dos discursos, práticas e instituições, e estes são dotados de dispositivos capazes de determinar nossa sexualidade e nosso gênero.

Como pensar então, as políticas curriculares, sob a égide das práticas discursivas da inclusão neoliberal, fora das instituições e discursos que produzem nossas sexualidades e nossos gêneros? Ou melhor, não estarão estas instituições e discursos interessados em dizer de nossa sexualidade? Não será útil a alguma fabulação dos interesses mercadológicos que as performances identitárias-sexuais, que historicamente foram marginalizadas, agora, nesta nova fase de acumulo do capital, sejam assimiladas e viabilizadas como normais?

\section{Inclusão, neoliberalismo e educação: tramas da produção de um discurso}

A denúncia histórica contra o processo de invisibilidade e violência contra a população LGBT, tem sido nas últimas décadas o motor de discussão sobre o reconhecimento de direitos desta população. Encontrar mecanismos de enfrentamento da violação dos direitos humanos destes indivíduos, então, tem se tornado uma pauta da sociedade, do Estado, dos movimentos sociais e de agenciais internacionais, dentre outras instituições. Neste contexto, a parceria entre movimentos sociais (especialmente os de minorias culturais) e o Estado, tem conduzido a formulações e implementações de políticas sociais, na educação, cultura e saúde, inseridas na lógica da inclusão neoliberal.

Agora, na sociedade contemporânea e no tombamento da modernidade, a reconfiguração do papel do Estado, dentre outras transformações políticas, se traduzem em novas formas de pensar, criar e implementar as políticas públicas sociais. No campo da educação, por sua vez, estes acontecimentos ancorados na lógica das reformas educativas 
neoliberais, reverberam na criação e implementação das políticas educacionais, especialmente, nas políticas curriculares, de educação em direitos humanos e inclusão.

Com estes acontecimentos, e pela preocupação do Estado do bem-estar social em dar respostas às demandas políticas das chamadas "minorias" culturais, e obviamente pelo movimento histórico de militância dos grupos sociais como o movimento negro, o movimento LGBTTT (Lésbicas, Gays, Bissexuais, Travestis, Transexuais e Transgêneros) e os movimentos feministas, que requeriam políticas públicas que atendessem suas demandas, culminou o surgimento de um discurso que ganhou destaque neste novo contexto de criação e implementação de políticas curriculares: a diversidade. A promulgação dos Parâmetros Curriculares Nacionais (PCNs), em 1997, com os temas "Pluralidade Cultural" e "Orientação Sexual", assim como a resolução CNE/CP Nº 1 , de 15 de maio de 2006, que institui as Diretrizes Curriculares Nacionais (DCNs) para o Curso de Graduação em Pedagogia, além disto, as Diretrizes Curriculares Nacionais para a Educação Infantil e para o Ensino Fundamental podem ser citados como exemplos de como a lógica da diversidade cultural se integrou nas políticas curriculares.

Em suas análises sobre o surgimento do uso do conceito de 'diversidade' nas políticas educacionais brasileiras, Rodrigues (2011), afirma que entre os anos 1940 e 1980, surgem novos paradigmas de sociedade, em contraposição ao modelo de nação/identidade nacional herdeira do século XIX. O Estado, segundo a autora, neste novo paradigma, em especial com as reformas constitucionais na américa latina, ganha uma caracterização diferente em relação ao seu papel, e passa a assumir responsabilidades com o chamado multiculturalismo, e multirracialismo. Já a partir dos anos 1990, com a eleição de Collor de Melo, e continuada no governo FHC, o Estado brasileiro passa a assumir uma face liberal em seus discursos e práticas. Neste contexto, as reformas na educação, saúde, direitos trabalhistas, tencionam para uma ruptura entre as gestão da economia, com as políticas sócias, ou seja, o Estado mínimo, que não interfere no mercado, passando a gestão das políticas sociais para os agentes não governamentais (RODRIGUES, 2011).

Este cenário político, ainda segundo Rodrigues (2011), ganha a atenção dos organismos internacionais, como a Organização das Nações Unidas para Educação, Ciência e Cultura (UNESCO), mobilizadas pelo significativo fenômeno de "afirmação" de identidades, sobretudo nas sociedades colonizadas pela Europa, estas agências internacionais, através de suas orientações, resoluções, documentos, passam a disseminar um discurso de "diversidade" cultural. É importante ressaltar que no contexto do Estado neoliberal, estas orientações passaram a ser assumidas pelo governo, implementando esta lógica nas políticas sociais brasileiras, em especial, nas políticas curriculares. Este cenário se materializa desde os anos 
1990, contudo, é a partir do governo Lula da Silva, que este discurso ganha mais substancia na aplicação de políticas para a diversidade sexual.

Neste campo discursivo que vem sendo produzido, as práticas de sujeição da sexualidade dos sujeitos estão sendo produzidas e redefinidas. A homofobia, por exemplo, tem sido objeto de constantes investidas discursivas para a compreensão deste fenômeno, e as possibilidades de enfrentamento. Não será pretensão, nesta pesquisa, a negação dos avanços para o reconhecimento de direitos historicamente negados aos abjetos da sexualidade heteronormativa. O investimento concentrado nesta trajetória, será a de compreender o que este discurso produz, e como atua sobre os corpos de que fala, assim como, produzindo um determinado discurso curricular para a educação básica.

As políticas públicas direcionadas ao enfrentamento da homofobia, especialmente, as políticas educacionais, assumem o discurso de 'diversidade sexual' em suas ações e estratégias. Poderíamos destacar aqui o Programa Federal Brasil Sem Homofobia, lançado em 2004, com estratégias direcionadas para vários campos de atuação, inclusive para a educação. No bojo desta política surgem outros programas e ações como o Programa Gênero e Diversidade na Escola, lançado em 2006, programa Saúde e Prevenção na Escola, lançado em 2006, programa Escola Sem Homofobia (ironicamente apelidado de Kit Gay), lançado em 2009, vetado, posteriormente.

Esta operação sobre uma verdade sobre o sexo de uma população, e neste caso, da população LGBT, está relacionado, obviamente, com um emaranhado discursivo, um conjunto de enunciados e dizeres que, entrelaçados e embebidos nas forças que constituem o poder-saber e, nas políticas sociais, são operadas como biopolíticas para o controle, regulação e docilização dos corpos desta população.

É certo que este emaranhado discursivo, no caso das práticas discursivas de um currículo para a educação básica, não está isolado de um contexto histórico e social que o produz, e de um dizer curricular, um dizer pedagógico, um dizer do sujeito cognoscente, um dizer da sexualidade, um dizer da inclusão, um dizer da política, que institui uma prática discursiva.

Para Lopes e Macedo (2008), as mudanças que vem acontecendo no quadro sociopolítico, econômico e cultural tem produzido uma nova dinâmica na produção de políticas para uma cultura mundializada. Estas transformações, sem dúvidas, são acompanhadas pela expansão/produção de uma sociedade da tecnologia da comunicação e da informação. Da mesma forma, este novo contexto tem alterado o próprio papel do Estado frente as demandas da sociedade. Estado este que, segundo as autoras, concebido no neoliberalismo global, passa a assumir uma função reguladora e gerencial da população. 
Com o intuito de obedecer aos interesses de uma hegemonia cultural e política da classe dominante, e pela instituição de novos parâmetros de conduta e de convivência, na sociedade e na escola, busca-se estabelecer estratégias, em grande medidas, resultantes de recomendações dos organismos internacionais, no intuito de " [...] formação de um novo cidadão, requerido por esse estágio de globalização.” (LOPES; MACEDO, 2008, p.9) que vão direta ou indiretamente reverberar na produção de novas políticas educacionais e a circulação de novos discursos para estas políticas. As autoras destacam ainda a centralidade do discurso curricular nas políticas educacionais contemporâneas e na produção de um novo sujeito da modernidade.

A produção de um determinado discurso (e neste caso de uma política curricular), precisa ser analisada por múltiplos olhares e lentes. Ou melhor, é necessário compreender que o discurso político-curricular é produzido por múltiplas forças e agentes que atendem determinados interesses, e estão atravessados por múltiplos agenciamentos e correlações de poder e saber.

Pode-se visualizar essas múltiplas forças quando compreendemos que as políticas curriculares para a diversidade sexual são construídas na confluência de diferentes agentes discursivos, como os organismos internacionais, agencias financiadoras de projetos e programas, o Estado, os movimentos sociais, sindicatos, escolas, associações, pesquisadores universitários, curriculistas, dentre outros. Esta movimentação do poder de produção de uma política é viabilizada pelas características do nosso tempo, onde não é mais possível o Estado como o grande produtor da força e poder que nos atravessa, mas pela capilaridade do poder, das microfísicas do poder.

Veiga-Neto (2011), ao problematizar as fissuras que as chamadas políticas de identidade e de inclusão tem acionado no discurso pedagógico atual, é cuidadoso ao dizer que não se trata de negar estas políticas e os avanços que elas tem proporcionado aos que historicamente tiveram suas vozes, ou mesmos seus corpos, negados na educação. É antes de tudo, uma tarefa de 'vigilância', na busca de procurar entender o que, e como, estas políticas tem produzido a partir do discurso da inclusão, dispositivos de controle e regulação dos corpos abjetos ao normal. A escola da modernidade (e suas promessas do sujeito do conhecimento), é a instituição onde se pode com mais potência, perceber as conexões entre poder e saber, "E é por causa disso que que ela é capaz de fazer tão bem a articulação entre a Razão de Estado e o deslocamento das práticas pastorais (para as tecnologias do eu), funcionando, assim, como uma máquina de governamentalização [...]" (VEIGA-NETO, 2011, p.109).

Sob o manto da inclusão, e suas políticas de identidade, a educação, em especial o discurso curricular, que já é atravessado por relações de poder, se torna uma arena de disputa 
ainda mais acirrado em busca de "incluir" este outro. Processo este, relacionado aos jogos de significação que a linguagem assume.

Os ditos "anormais" e suas difusas identidades, como a população LGBT, precisam ser identificados, classificados e assimilados dentro de uma suposta diversidade humana. Assim, o "anormal" é constituído por oposição ao "normal", ou melhor, tudo aquilo que foge de uma suposta normalidade (atravessadas pelos processo de significação da linguagem - o que é normal?) são arrastados para a zona do "anormal”, aquilo/aquele que não é legitimado, mas que precisa ser incluído, pois, se encontra no domínio do que é diverso (ao normal).

Skliar (2003), na tentativa de buscar capturar as imagens do outro "Outro", nos discursos pedagógicos da educação brasileira, regurgita as perguntas que incessantemente se faz ao outro e a educação; que/quem é o outro? Este outro nunca esteve aqui? Este outro nos confronta apenas para contar e denunciar sua história de exclusão? E, o que quer este outro?

A pergunta que faz pelo outro, e a questão que se interpela na educação se faz sempre pela reforma do mesmo, com uma nova roupagem, como uma maquiagem, sobre outra maquiagem. Não se busca, ou se tem buscado até aqui, a mudança nos pontos de partida e de visão deste outro, mas apenas a relocação de normas, leis, estatutos, éticas, currículos, projetos educacionais, propostas pedagógicas, mas nada ainda sobre o encontro-atravessamentovibração com este outro.

As políticas da tolerância que tem se materializado nos discursos da diversidade, tem reivindicado a posição de um indivíduo de caráter privilegiado, o indivíduo igual, em detrimento do reconhecimento e da assimilação de certos outros tipos de grupos, o outro não igual ao mesmo. A tolerância, como modo de assimilar o outro da inclusão pode vergar as diferenças discursivamente produzidas, em nome de um apaziguamento das desigualdades sociais (DUSCHATZKY, 2011). Não questionando a exclusão, e nem os mecanismos de produção desta. Mas, ao contrário, procurando esquece-los em nome de uma urbanidade e simpatia.

$\mathrm{Na}$ educação, e no discurso curricular, a tolerância pode operar como uma desmemorização das históricas e culturais produções da diferença e da desigualdade social. Tolerando os outros que precisam ser cuidados, incluídos, acolhidos, pela sua "má sorte". Ou melhor, precisam ser "aceitos" nas suas diferenças para com o comum. Abrindo terreno para a naturalização da tolerância com o menor, o estranho que precisa de ajuda.

E onde está a produção de um sujeito LGBT? Onde está a produção desta população? Não é em outro lugar se não nas práticas que dizem de um sujeito não convencional. Nos documentos que dizem de um "sujeito de direitos". Que dizem sobre suas necessidades, suas características. E que definem quem é, e quem não é a depender da performatividade gênero- 
sexual. É lá que se encontram os enunciados produtores destes modos de vida. E é lá que se encontram as resistências. Onde há currículo, há resistência. Reconhecendo os discursos políticos curriculares como forças produtoras de determinado sujeitos, é imprescindível reconhecer também que é por dentro das instituições que se fazem os jogos de poder e as vontade de saber. E o currículo como um dispositivo que articula um conjunto de estratégias para construir um desejo-sujeito. Mas o currículo sempre "quer" alguma coisa. E se ele "quer", ele deseja, ele tem vontade, ele tem fetiches.

Sierra (2013) ao descrever a relação que tem se estabelecido entre o discurso da diversidade sexual e os dispositivos de biopolíticas no campo da elaboração de políticas educacionais, indica que, nesta nova configuração, estas práticas discursivas acabam por produzir dispositivos e mecanismos de governamentalidade dos modos de vida, capturando as diferenças sexuais. Para o autor, os movimentos sociais contemporâneos, sobretudo os grupos provenientes das chamadas "minorias culturais", atuam a partir de dinâmicas organizadas pela requisição das suas demandas a partir do reconhecimento de suas características específicas, ou, pela representação de suas identidades. A educação, por exemplo, é um campo em disputa e de lutas sociais onde vários grupos minoritários demandam pela sua representação, seja na produção do conhecimento escolar, seja pela inclusão destes grupos escola.

$\mathrm{Na}$ última década, as demandas sociais pela inclusão e pela representação de determinadas culturas no currículo escolar, foram protagonizadas pelos movimentos sociais. Nestas novas alianças entre o Estado e os movimento LGBT a exemplo das políticas para a diversidade sexual, observa-se a configuração de estratégias biopolíticas e de governamentalidade da população LGBT. Este movimento acaba por engessar uma movimentação de crítica dos próprios movimentos sociais, que acabam por se verem representados nas atuais políticas, resultando em muitas vezes em uma participação mais branda, e menos crítica nos resultados obtidos. Por outro lado, a matriz estabelecida como parâmetro de diretrizes, encontra-se, em muitos casos, configurada a partir de caracterizações heteronormativas.

É neste contexto da emergência do discurso da diversidade, atrelada a uma concepção de respeito e tolerância e de processos identitários que surgem as políticas de inclusão para a população LGBT. Essas políticas, segundo ainda Sierra (2013), buscam encontrar mecanismos de controle e regulação dos sujeitos LGBT. Marcos de governamento desta população como estratégias de conciliar os embates e atritos pelos projetos de modos de vida legitimados. Neste horizonte, as políticas inclusivas para a diversidade, tem produzido um processo hegemonizador dos corpos e das práticas sexuais, das formas de ser e viver, das formas prazerosas, de desejo, afetividade. 
Pode-se, considerar então, a partir de uma leitura foucaultiana, que as políticas de inclusão para a população LGBT, ao tomar este seguimento como sujeitos de direito, operam por duas direções em seus discursos e práticas. A primeira é de reconhecer os direitos civis a esta população; direitos que estão relacionados a militância histórica do movimento homossexual que, sem dúvidas, foi e ainda é muito importante para a conquista destes direitos. A segunda direção opera no sentido oposto ao reconhecimento destes diretos, pois, segundo Sierra (2013), estas políticas estão numa lógica de "dou com uma mão, e tiro com outra", estabelecendo regulações e formas normalizadoras para o reconhecimento das identidades de gênero e sexuais. Em outras palavras, o autor aponta que esta segunda direção das políticas de inclusão para os LGBT, opera em uma espécie de captura identitária desta população, pois cristaliza um modelo de identidade que deve ser seguido para que esses direitos sejam reconhecidos. Estes mecanismos acabam produzindo um sujeito digno, correto, e que só merecerá este reconhecimento de direitos se estiverem dentro de determinadas características.

\section{Outras vidas são possíveis: aproximações finais}

De forma geral, o discurso de diversidade sexual nas políticas curriculares sob o olhar das ferramentas analíticas das teorizações foucaultianas e do pensamento da Diferença em Educação, revelam-se como discursos de produção de identidades fixas, provenientes de um multiculturalismo liberal impregnado nas políticas públicas educacionais contemporâneas. Lopes e Macedo (2011), alertam que as políticas curriculares, o currículo em si, bem como as políticas de identidade contidas nele, são um campo para se pensar na Diferença, para além da identidade e da diversidade. Para as autoras, as recentes reivindicações dos movimentos identitários como o movimento negro, indígena, feminista e LGBTTT, vem já a algum tempo, clamando por outras maneiras de se perceberam a identidade a hierarquizações destas, contudo, nos alertam também que estas constantes reivindicações destes movimentos por políticas de identidade podem ser estabelecidos a partir de pontos fixos, pertencimentos, e muitas vezes, por discursos marcados por essencialidades. É neste bojo que as políticas de diversidade sexual, por exemplo, são ancoradas no discurso de combate a homofobia, onde é necessária uma narrativa de "múltiplas" identidades, onde as identidades são diversas, plurais, porém, finitas, fixas, controladas. As autoras propõem que tanto nas políticas curriculares, quanto nas políticas de identidade do currículo, é preciso ir além da identidade.

No mesmo espírito, Silva (2014), ao propor uma pedagogia como Diferença, afirma que não é coerente pensar uma educação sob o prisma de um multiculturalismo que parte de uma lógica de respeito e tolerância com o diferente. Para o autor, esta visão impede que percebemos 
o processo de produção da diferença como processos históricos e sociais e que partem das relações de poder. Paraíso (2010), neste encontro, argumenta que é preciso dar um "adeus" à identidade, na pretensão de um currículo, de uma política e uma prática cultural que vibre, dance e pulse. Dar adeus à identidade, segundo a autora, é apostar em pretensões de Diferença, é apostar em outras práticas e discursos para a cultura, gênero, sexualidade.

Para além destes apontamentos, o objetivo principal de pesquisa desta escrita não se contentou em tentar captura e flagrar a forma como procede o governamento das condutas e das performances de gênero e sexualidade nos dispositivos de controle operados pelas técnicas de si, nas políticas curriculares para a educação básica. Com projeções de olhares para além destas delimitações e hierarquizações, é preciso também observar que o conceito de poder em Foucault é difuso e não unilateral. Desta forma, há sempre resistências, há sempre linhas de fuga, há sempre potências performáticas que fogem dos binarismos e estereótipos. Há sempre vontades de verdade.

Isso nos faz pensar em uma outra prática discursiva que esteja atenta, talvez a essas potencialidades performáticas de sujeitos-afectos, que vá além das delimitações históricas e culturais sobre as estéticas de existência. Há sempre potência, no devir-ser/existir. É preciso comprometer-se também em a achar estas linhas de fuga, as resistências, as outras performances de éticas e estéticas de existência que essas políticas não dão conta. Aquilo que não pode ser nomeado, pois, é uma potência, é um devir. Uma estética outra, que não pode ser governada.

Embora estas políticas tenham a finalidade de domesticar estes corpos e mentes, é preciso sempre encontrar as brechas, as fissuras, as linhas de fuga, as resistências e potências performáticas de gênero e sexualidade, ou como Foucault aponta, as estéticas de existências, que estas políticas não alcançam.

O que cabe, então, é problematizar este discurso da diversidade sexual, e as práticas discursivas, assumido nas políticas curriculares contemporâneas. Objetivando problematizar este discurso, colocá-lo sob desconfiança e, a partir dele, pensar nas políticas curriculares para a diversidade sexual, pensar na identidade, porém, almejando a diferença, para outros modos de vida.

\section{Referências}

BUTLER, Judith. Problemas de gênero: feminismo e subversão da identidade. Rio de Janeiro: Civilização Brasileira, 2008.

-BUTLER, Judith. Relatar a si mesmo: crítica da violência ética. Belo Horizonte: Autentica. 2015. 
-CORAZZA, Sandra. O que quer um currículo?: pesquisas pós-críticas em Educação. Petrópolis: Vozes, 2001.

-COSTA, Marisa Vorraber. Poder, discurso e política cultural: contribuições dos Estudos Culturais ao campo do currículo. In: LOPES, A. C. MACEDO, E. Currículo: debates contemporâneos. São Paulo: Cortez, 2010.

-DUSCHATZKY, Silvia. O nome dos outros: Narrando a alteridade na cultura e na educação. In: LARROSA, Jorge; SKLIAR, Carlos. Habitantes de Babel: políticas e poéticas da diferença. 2 ed. Belo Horizonte: Autentica Editora. 2011.

FOUCAULT, Michel. Microfísica do poder. Rio de Janeiro: Graal, 1979.

FOUCALT, Michel. História da sexualidade I. A vontade de saber. 2 ed - São Paulo: Paz e Terra, 1989.

LOPES, Alice Casimiro; MACEDO, Elizabeth. Teorias de Currículo. São Paulo: Cortez, 2011.

LOPES, Alice Casimiro; MACEDO, Elizabeth. Políticas educativas e dinâmicas curriculares no Brasil e em Portugal. Petrópolis: DP, Faperj, 2008.

-LOURO, Guacira Lopes. Currículo, gênero e sexualidade: o "normal" o "diferente" e o "excêntrico". In: LOURO, Guacira Lopes (Org). Corpo, gênero e sexualidade: um debate contemporâneo na educação, 9. Ed. Petrópolis: Vozes, 2013.

PARAÍSO, M. A. Diferença no Currículo. Cadernos de Pesquisa. v.40, n.140, p. 587-604, maio/ago. 2010.

RODRIGUES, Tatiane C. A ascensão da diversidade nas políticas educacionais contemporâneas. (Tese Doutorado em Educação) UFSCar, 2011.

SIERRA, Jamil Cabral. Marcos da vida viável, marcas da vida vivível: o governamento da diversidade sexual e o desafio de uma ética/estética pós - identitária para teorização política educacional LGBT. Tese de Doutorado (Doutorado em Educação). Universidade Federal do Paraná. Curitiba, 2013.

SILVA, Tomaz Tadeu da. A produção social da identidade e da diferença. In: SILVA, Tomaz Tadeu da. Identidade e Diferença: a perspectiva dos Estudos Culturais. Petrópolis: Vozes, 2014. p. 73-102.

SKLIAR, Carlos. A educação e a pergunta pelos Outros: diferença, alteridade diversidade e os outros “outros". Ponto de Vista, Florianópolis, n. 05, p. 37-49, 2003.

VEIGA-NETO, Alfredo. Incluir para excluir. In: LARROSA, Jorge; SKLIAR, Carlos. Habitantes de Babel: políticas e poéticas da diferença. 2 ed. Belo Horizonte: Autentica Editora. 2011 